\title{
Formulation of Cell Growth Inhibition by Chemicals and Environmental Agents
}

\author{
By J. SCHUBERT \\ Department of Radiation Health, Graduate School of Public Health, \\ University of Pittsburgh, Pittsburgh, Pennsylvania I5213, U.S.A.
}

(Accepted for publication 1o September 1970)

\begin{abstract}
SUMMARY
Equations are developed in which the inhibition of cell growth by different levels of a given chemical or environmental agent is expressed by a single straight line. The formulation provides a simple, economic, and consistent way of characterizing different growth inhibitors and evaluating their possible mechanisms of action, e.g. structure-activity relationships.
\end{abstract}

\section{INTRODUCTION}

The growth rate of bacteria and cells in general is decreased by a variety of chemicals and environmental agents (Clifton, 1957; Dean \& Hinshelwood, 1966). As no satisfactory or consistent procedure exists for comparing the degree of growth inhibition by different agents, investigators have often presented numerous graphs in which they simply plotted some measure of cell growth versus time for each concentration or energy unit employed. Others, in an attempt to obtain a straight line relationship, plotted an arbitrarily chosen index of growth at a given time versus the logarithm of the concentration, or energy units. Monod (1949) employed a growth lag constant, $L$, defined as the difference in number of divisions between observed and ideal growth during the exponential phase.

The approaches cited above, and others which have been employed to evaluate growth inhibition (see Dean \& Hinshelwood, 1966, for details) possess many disadvantages, e.g. (a) they are useful only for comparisons under a given set of experimental conditions; $(b)$ the concentrations of inhibitors are expressed on a volume basis without regard to the number of cells initially present; $(c)$ the choice of growth phase used as an index of base line is often arbitrary.

It seems best to evaluate true growth inhibition at a time as close to the initial conditions as is practically possible, a point stressed by Monod (I949). In this connexion it is important to recognize that the concentration per cell of a chemical agent is constantly changing as cell number increases. Therefore, criteria of growth inhibition which encompass the exponential phase become meaningless when one considers that exponential growth following inhibition may reflect additional factors such as destruction or modification of the primary action.

In investigations on the effects of irradiated media and chemical agents on the growth of Salmonella typhimurium LT 2 (Schubert, Watson \& White, 1967; Schubert \& Watson, I969; Schubert, Watson \& Baecker, 1969; Watson \& Schubert, 1969) it was necessary 
to compare the inhibitory actions of different agents on bacterial growth. The formulation described here has been found to be a simple, economic and consistent formulation of expressing the degree of growth inhibition as a linear relationship over practically the entire range of concentration of inhibitor.

\section{FORMULATION}

Consider the bacterial growth curve (Fig. I) in which the number of bacteria in $\log _{2}$ units is plotted against time. Curve 0 represents bacterial growth in absence of added inhibitors, and curve $A$ represents bacterial growth when inhibitor $A$ is present. One $\log _{2}$ unit corresponds to a doubling of cell number.

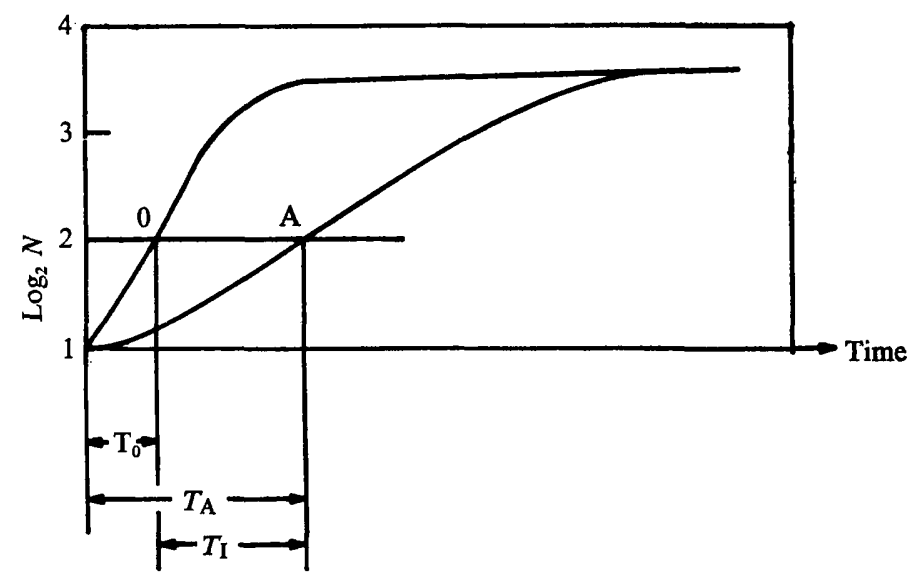

Fig. I. Schematic growth curve for bacteria following inoculation in which $N$ represents number of bacteria. Curve $o$ is the growth curve when the concentration of inhibitor is zero; $T_{0}$ represents the doubling time, $T_{\mathrm{A}}$ is the doubling time in the presence of inhibitor A; and $T_{1}$ is the net initial doubling time.

In the control samples the concentration of inhibitor is zero, and the doubling time is expressed by $T_{0}$, while $T_{\mathrm{A}}$ is the doubling time when a finite concentration of inhibitor $\mathrm{A}$ is present. The initial doubling time, $T_{\mathrm{I}}$, is defined as follows:

$$
T_{\mathrm{I}}=T_{\mathrm{A}}-T_{0},
$$

where

$$
T_{\mathrm{A}}>T_{0} \text {. }
$$

It is seen, therefore, from equation (I) and from Fig. I that $T_{\mathrm{I}}$ represents the net increment of growth inhibition or delay produced by a given concentration of inhibitor. As the concentration of inhibitor A increases, the value of $T_{1}$ increases. Expressed as a simple differential equation we may assume that

$$
\frac{\mathrm{d} T_{\mathrm{I}}}{T_{\mathrm{I}}}=\lambda \mathrm{d} C,
$$

where $\lambda$ is a constant and $C$ is inhibitor concentration in $\mu$ moles/cell.

Integration gives

$$
\ln T_{\mathrm{I}}=\lambda[C]+\ln T_{\text {ext }}
$$


or expressed in logs to the base ten

$$
\log T_{\mathrm{I}}=\frac{\lambda[C]}{2 \cdot 303}+\log T_{\mathrm{ext}}
$$

where $\lambda / 2 \cdot 303$ and $\log T_{\text {ext }}$ are the slope and intercept respectively of the straight line obtained when $\log T_{\mathrm{I}}$ is plotted against $[C]$.

Expressing equation $(3 b)$ in terms of the doubling concentration $\left[C_{2}\right]$, i.e. the incremental concentration of $[C]$ which doubles $T_{\mathrm{i}}$, we obtain

$$
\log T_{\mathrm{I}}=\frac{0 \cdot 30}{\left[C_{2}\right]}[C]+\log T_{\text {ext. }}
$$

Accordingly, a semilog plot of $T_{\dot{\mathbf{i}}} v .[C]$ should yield a straight line with slope proportional to $\left[C_{2}\right]$. Upon extrapolation to $[C]=0$, the intercept on the $T_{\mathrm{I}}$ ordinate gives the value of $T_{\text {ext }}$ (Fig. 2). To simplify, note that $T_{\mathrm{I}}=2 T_{\text {ext }}$ when $[C]=\left[C_{2}\right]$.

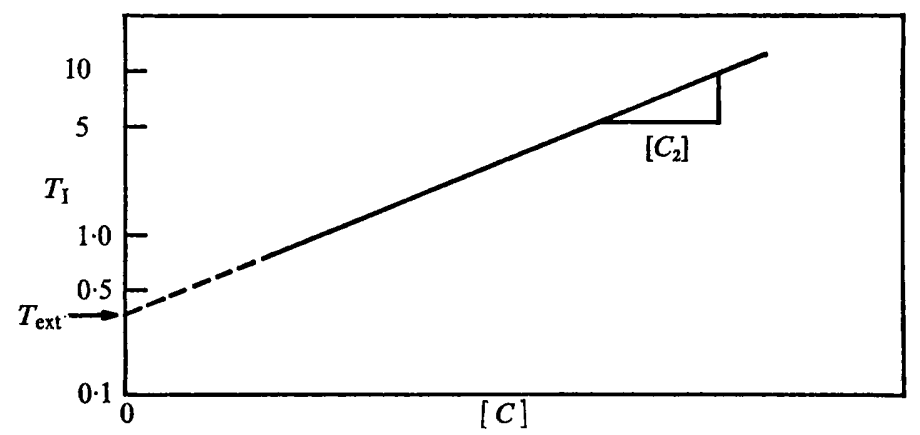

Fig. 2. Schematic diagram of a plot of $\log T_{1} v$. initial concentration, [C], following equation (3c).

Equation $(3 c)$ applies over practically the entire range of measured inhibition for finite positive values of $[C]$. However, since $T_{\mathrm{r}}=0$ when $[C]=0$, deviation from the straight line must occur at very low values of $[C]$, and usually does in the region where $T_{\mathrm{I}}$ is too small to be measured reliably, e.g. where $T_{\mathrm{I}}$ differs by $5 \%$ or less from $T_{0}$. More precisely, deviation from the straight line will occur at concentrations approaching the threshold concentration $\left[C_{\mathrm{t}}\right]$, the value of which can usually be estimated from the experimental data.

The relative inhibitory activity of different substances is conveniently expressed by a single term, namely the concentration of inhibitor for which $T_{\mathrm{I}} \approx \mathrm{I} O T_{0}$. Thus, in my system, I find that self-consistent results are obtained by the use of $C_{10 \mathrm{~b}}$, i.e. the concentration at which $T_{\mathrm{I}}=$ ro hours.

\section{DISCUSSION}

The formulation described here has provided a convenient means for evaluating the relative growth inhibition by varying concentrations of chemical agents. An added advantage of the formulation is its expression in terms immediately identified with the experimental system. Further, less time is needed to evaluate relative growth inhibition since it usually suffices to measure growth rates only for the time needed for the cells to undergo one doubling time following inoculation. 
I have applied equation $(3 c)$ to data on the inhibitory action of different classes of chemical agents including carbonyl compounds on the growth of Salmonella typhimurium LT 2 using methods described previously (Schubert et al. 1967). Some representative values of $\left[C_{2}\right]$ (in units of $10^{-8} \mu$ moles/cell) and $T_{\text {ext }}$ for carbonyl compounds are formaldehyde, $\left[C_{2}\right]=0.1 \mathrm{I}, T_{\text {ext }}=0.053$; acetaldehyde, $\left[C_{2}\right]=6.4, T_{\text {ext }}=0.25$; glycolaldehyde, $\left[C_{2}\right]=\mathrm{I} \cdot 6, T_{\text {ext }}=0.03 \mathrm{I}$; and glyceraldehyde, $\left[C_{2}\right]=4 \cdot 0, T_{\text {ext }}=0.18$. The experimental data for a variety of chemical agents including $\mathrm{H}_{2} \mathrm{O}_{2}$ will be published at a later date.

Equation ( $3 c$ ) has been found to apply to systems other than those mentioned here, e.g. Escherichia coli (Együd, 1967), and to the effect of irradiation on the growth of mammalian cells in culture (Elkind \& Whitmore, 1967). In the latter case, we can plot $\log T_{\mathrm{I}} v$. energy units absorbed. However, if it is suspected or known that the radiationinduced inhibition is due to the formation of a given compound or class of compounds and the radiation yield is known, then the energy units can, of course, be converted to $\mu$ moles. For example, I have obtained linear $\log T_{\mathrm{I}} v .[C]$ plots for the antibacterial action of irradiated sucrose solutions for radiation doses in the range of 0.05 to $5.0 \mathrm{Mrad}$. where $[C]$ was expressed in terms of the total concentration of carbonyls produced by radiolysis.

This investigation was supported by the U.S. Atomic Energy Commission, Division of Biology and Medicine, under AEC contract AT(30-I)-364I and by contract FDA 68-29 with the Division of Food Chemistry, Bureau of Science, Food and Drug Administration, Department of Health, Education and Welfare, Washington, D.C.

I am indebted to several colleagues for encouragement and stimulating discussions, especially Professors A. Brodsky, C. Ke, D. Sashin, J. A. Watson, C. C. Li, and Mr Sanford Markowitz.

\section{REFERENCES}

Clifron, C. E. (1957). Introduction to Bacterial Physiology, ch. 13, I4. New York: McGraw-Hill.

DeAn, A. C. R. \& Hinshelwood, C. (1966). Growth, Function and Regulation in Bacterial Cells. Oxford: Clarendon Press.

EGYüD, L. G. (1967). Studies on cell division: the effect of aldehydes, ketones and $\alpha$-keto-aldehydes on the proliferation of Escherichia coli. Currents in Modern Biology I, I4.

ElKind, M. M. \& WhitMoRE, G. F. (1967). The Radiobiology of Cultured Mammalian Cells. New York: Gordon and Breach.

Monod, J. (1949). The growth of bacterial cultures. Annual Review of Microbiology 3, 371.

Schubert, J., WAtson, J. A. \& White, E. R. (1967). Hydroxyalkyl peroxides and the toxicity of irradiated sucrose. International Journal of Radiation Biology 13, 485.

SChUBERT, J., WATSON, J. A. \& BAECKER, J. M. (I969). Formation of a histidine-peroxide adduct by action of $\mathrm{H}_{2} \mathrm{O}_{2}$ or ionizing radiation on histidine: chemical and microbiological properties. International Journal of Radiation Biology $\mathbf{1 4}, 577$.

SCHUBERT, J. \& WATSON, J. A. (1969). Organic peroxides and the antibacterial action of irradiated sucrose as affected by catalase. Radiation Research 37, 531 .

WATSON, J. A. \& SCHÜBERT, J. (1969). Action of hydrogen peroxide on growth inhibition of Salmonella typhimurium. Journal of General Microbiology 57, 25. 